\title{
First in-situ nitrogen isotope measurements in Martian meteorites
}

\author{
CÉCILE DELIGNY ${ }^{1}$, EVELYN FÜRI ${ }^{2}$, ETIENNE \\ DELOULE $^{3}$ AND ANNE PESLIER ${ }^{4}$
}

${ }^{1}$ Université de Lorraine-CRPG-CNRS

${ }^{2}$ Université de Lorraine/CNRS

${ }^{3}$ CRPG-CNRS-UL

${ }^{4}$ NASA-Johnson Space Center

Presenting Author: cecile.deligny24@gmail.com

The origin and timing of the accretion of volatile elements on the terrestrial planets remains a subject of controversy. Nitrogen and hydrogen isotopes are powerful tools to constrain the source(s) of primordial volatiles accreted by planetary bodies because their isotope ratios $\left({ }^{15} \mathrm{~N} /{ }^{14} \mathrm{~N}\right.$; D/H) differ significantly between different solar system reservoirs (e.g., solar, chondritic, cometary). Hf-W data of martian samples indicate that Mars accreted very rapidly in the inner solar system and reached half of its size in 1.8 Myr [1]. Therefore, martian samples are key to understand the distribution of volatile elements in the inner solar system during the early stages of planetary formation. Since no space missions have yet returned samples from Mars, martian meteorites (Shergottites, Nakhlites, Chassignites) are unique samples to constrain the source(s) of volatiles present in the martian mantle. The goal of this study was to target pristine phases (e.g., melt inclusions, mesostasis) for in-situ measurements of their nitrogen content and isotopic ratios to access the most primitive melt of the Chassignites and Nakhlites reservoirs. Five different Nakhlites (Nakhla, NWA 998, MIL 03346, Y 000593, NWA 6148) and Chassigny were analysed [2] using a recent high-resolution analytical technique that allows constraining the nitrogen composition of both carbon-bearing and carbon-free phases in natural and synthetic samples. Nitrogen was measured in the form of ${ }^{14} \mathrm{~N}^{16} \mathrm{O}^{-}$and ${ }^{15} \mathrm{~N}^{16} \mathrm{O}^{-}$with the CAMECA 1280-HR2 at the CRPG [3]. A significant amount of nitrogen was detected in melt inclusions in Chassigny and in the mesostasis of Nakhla, Y 000593, MIL 03346, and NWA 6148. Nitrogen isotope signatures of Chassigny and Nakhlites exhibit a heavy isotope enrichment compared to Earth's mantle, and are consistent with a carbonaceous chondrite-like source [4]. This suggests that Earth and Mars accreted nitrogen from different chondritic sources. Overall, our in-situ technique is a unique and powerful tool to characterize the nitrogen abundance and isotopic composition of natural samples.

\section{References:}

[1] Dauphas \& Pourmand (2011) Nature 473, 489. [2] Peslier et al. (2019) GCA 266, 382-415. [3] Füri et al. (2018) Chem Geol 493, 327-337. [4] Alexander (2017) Philos $T R$ Soc A 375, 20150384. 